\title{
Transformative Learning: Developing Agency, Independence and Promoting a Strong Sense of Self in Teen Mothers
}

\author{
Lilliemay Cheung \\ University of Queensland, Australia \\ Emma Kill \\ University of the Sunshine Coast, Australia \\ Janet Turley \\ University of the Sunshine Coast, Australia
}

\begin{abstract}
Adolescents who become pregnant during their secondary education experience a range of challenges that intersect and limit their opportunities to complete schooling and take up university places. One approach to addressing this issue at an Australian regional university is through the Tertiary Preparation Pathway (TPP) which has been delivered within the Supporting Teenagers with Education, Mothering, and Mentoring (STEMM) program, since 2008. The STEMM program offers teen mothers an opportunity to continue or re-engage with education during and beyond pregnancy. Adopting an intersectionality lens, interviews with adolescent mothers identified three key elements underpinning the success of the TPP/STEMM program: recognising the educational aspirations of teen mothers, developing agency and independence and promoting a strong sense of self. This article aims to provide practical implications for educators wishing to establish or develop programs based on this transformative teaching.
\end{abstract}

Keywords: Tertiary preparation pathway; teenage mothers; mentoring; secondary education.

\section{Introduction}

Despite a growing body of evidence that suggests supportive pathway programs offered in secondary and tertiary education help marginalised students to graduate from university (Watson \& Vogel, 2017), the reality is that many young mothers do not. Adolescents who become pregnant during their years in secondary education experience a range of challenges that intersect and limit their opportunities to complete schooling and take up university places. Supporting adolescent mothers attending university requires a substantial range of supports and an approach to teaching that often falls outside the range of traditional approaches associated with graduate success and educational program funding.

One approach to addressing this issue at an Australian regional university, is the Tertiary Preparation Pathway (TPP) which is part of a series of enabling programs delivered nationally. The regional university has been delivering TPP within the Supporting Teenagers with Education, Mothering, and Mentoring (STEMM) program, in partnership with Education Queensland since 2008. The STEMM program offers teen mothers an opportunity to continue or re-engage with education during and beyond pregnancy. Most of these students face major barriers to learning resulting from a disrupted education.

This work is licensed under a Creative Commons Attribution 4.0 International Licence. As an open access journal, articles are free to use with proper attribution. ISSN: 2205-0795 
Lessons learnt from the development and implementation of the program reveal that traditional educational institutional practices require a more flexible and connected approach to address the learning challenges these young students face due to both structural barriers and stigma (Seamark \& Lings, 2004; Yardley, 2008).

The program brings together three essential platforms for transformation. First, it addresses education as an important societal right and as a gateway to accessing economic, social and cultural capital. Second, the program enables the development of agency and independence often in the face of disempowerment, disadvantage, and social exclusion for the teen mothers. Third, the TPP/STEMM program promotes the development of a sense of self-worth that enables teen mothers to re-engage in their dual role as a tertiary student with parenting responsibilities. Reconciling the intersections of the social expectations and individual aspirations of these different roles requires a deeper understanding of how these tensions are experienced by the teen mothers and responded to by the service providers from a range of institutions and agencies providing the support. Opportunities often also present risks, both in terms of delivering the program as well as participating in it.

This article examines the value of the program and investigates how to better understand these intersections and to reconcile incongruent or incompatible expectations. In doing so it provides a better understanding of the complexity and intersectional tensions that teen mothers experience in relation to broadly accepted discourses related to education, motherhood and adolescence.

\section{Literature Review}

\section{Student Experience}

The student experience is a state of adjusting to and learning at university (Barnett, 1997). It requires students to invest in developing knowledge and to engage in the process of learning about themselves through self-reflection and being able to transform the world through critical action (Crème, 1999). Taking this view of the student experience as a state of developing this knowledge and becoming a critical being (Dunne, 2015) requires students to become resilient in the face of adversity and to be able to persist throughout the university journey. However, this research has not considered vulnerable groups specifically. There is a gap in research relating to teen mothers' educational experiences (Butler et al., 2010; Watson \& Vogel, 2016). Until recently, too many educational researchers have relied on unfounded assumptions that pregnant and mothering teenagers have low aspirations for educational and vocational pursuit (Graham \& McDermott, 2005; Yardley, 2008). This has played into the formulation of educational policy that disregards this cohort of students (Duncan, 2007), and along with traditional enrolment and participation expectations of tertiary institutions represents the types of structural barriers that persist for teen mothers entering and succeeding at university.

\section{Motherhood Educational Aspirations}

Teenage parenting is generally deemed as a social problem in modern cultures (Pillow, 2006). Teen mothers are often portrayed in cultural references as a homogenous group, that are single, irresponsible, immature, unfit parents who rely on welfare and have limited life choices (Yardley, 2008). However, in contrast teen mothers themselves view the birth of their child as personal affirmation resulting in high life expectations (Duncan, 2007). Often, adolescent mothers see the birth of a child as the inspiration or catalyst for increased educational or occupational advancement (Carlson, 2016; Smith-Battle, 2007). Teen mothers feel no less competent than their older counterparts and are determined to find employment to ensure future economic independence (Duncan, 2007). Indeed, many teen mothers work harder to achieve better grades to ensure college acceptance (Kendall et al., 2005; Schultz, 2001). However, research does identify a significant gap between assumptions held by professionals about the aspirations of teen mothers and their forecasts of this cohort's educational prospects (Pillow, 2004; Smith-Battle, 2007).

\section{Stigmatised Students}

Stigma marks an individual as "different from others and of a less desirable kind ... reduced in our minds from a whole or usual person to that of a tainted, discounted one" (Goffman 1963. p. 5). Stigma manifests as stereotypes and labels, resulting in discrimination, a reduction in status and social isolation (Link \& Phelan, 2001; Major \& O'Brien, 2005). Adolescent mothers who stay in school express greater stigmatisation than those that have left (Bermea et al., 2018). The intersection of age and 
parenthood results in negative stereotypes and judgement, which leads to the mothers experiencing discrimination from educational and healthcare professionals over the course of their pregnancy and parenthood (Conn et al., 2017). In the school setting, discriminatory practices relating to a lack of tolerance to class attendance or absence made it very difficult for parenting mothers to care for their child, express breast milk or even feed their children during school sessions. Cultural stereotyping and non-reflexive examination of values and beliefs within educational settings limit the flexibility or consideration of the adolescent's parenting role (Bermea et al., 2018). To date, there is a paucity of evidence to assist educators to better understand the barriers facing young mothers enrolled in tertiary education.

\section{Theory}

The theory of intersectionality has been increasingly used to understand the complexity of social and political forces that impact on and influence social change in institutionalised settings (Collins \& Bilge, 2016). Intersectionality is concerned with addressing issues related to social inequality that can be located via positions of social class, economic and social context, and relational opportunity. Contemporary educational research can use intersectionality to study how social categories function as tools of stigma and discrimination, through the perpetuation of social exclusion and hierarchical positioning in daily interactions (Connor, 2006; Staunaes, 2003). Extending prior research and adopting an intersectionality lens (Allard \& Santoro, 2008; Irizarry, 2007), the current research aims to inspire research and practice that transforms pedagogical relationships in the university context.

Intersectionality and transformative learning and teaching share historical connections. In accord with the philosophy critical pedagogy inspired by the works of Freire (1970), teachers working with young women with parental responsibilities need the time and space to explore how cultural stereotyping and neoliberalism impact on career choice and employment prospects. The practice of teaching, that is, the critical pedagogy matters because interaction and engagement in classrooms can either relieve or entrench structural positions of disadvantage. According to Taylor (2008), transformative teaching is a theory of existence, which views people as subjects, not objects, subjects who are constantly reflecting and acting on the transformation of their world so it can become a more equitable place for all to live. Freire (1970) was clear that education can be used as a force of oppression that simply reproduces assigned places in existing social hierarchies (Collins \& Bilge, 2016). Critical pedagogy research provides an opportunity to examine and negotiate how teachers and students come to understand themselves and the world through their experience.

\section{Method}

Qualitative research was conducted to better understand how the university experience of teen mothers. Ethics approval was obtained for the university's Human Research Ethics Committee prior to conducting the interviews. Twenty-two, in-depth interviews with participants of the TPP/STEMM program were conducted. An interview guide contained open-ended questions designed to allow the informants the time and flexibility to explore the thoughts and views of the participants in relation to their experience of the TPP/STEMM program. We sought to understand: the motivation for entering into the program, client expectations from the program, understandings of service offerings and limitations, and the types of activities and practices that supported or detracted from the teen mother's experience at university. The data were collected between March 2017 and June 2018. Interviews ranged in length from 45 to 180 minutes.

All of the interviews were audio-recorded and transcribed verbatim. The qualitative data were analysed using an interpretivist, hermeneutical approach (Thompson, 1997). The researchers read each transcript in its entirety several times with the intention of understanding how the experiences, thoughts and emotions represented consistent themes or motifs. The analysis was also informed by the secondary data reviewed over the period of research which was essential to represent the dynamic context of this social issue (Spiggle, 1994; Thompson, 1997). Next a coding framework was developed from the themes gleaned from reading the transcripts from the participants' accounts. Themes were compared to and informed by the secondary literature in line with the critical theoretical approach of intersectionality (Collins \& Bilge, 2016). All data were subject to an iterative process of multiple cycles of coding and refining as new concepts emerged inductively from the data. Each actor's interview data was subject to constant comparison to other participant accounts to create consistent, reliable themes while also being sensitive to alternate perspectives or new ideas (Spiggle, 1994; Thompson, 1997). Verbatim quotes are used to illustrate the themes. 


\section{Findings}

The participants in this study engaged critically with the role of education in their lives, their developing sense of agency and building a stronger sense of self that came from their university experience as part of the TPP/STEMM program. Each of the excerpts from the transcripts speak to a particular reflection made by one of the participants yet reflect a broader consensus of the value of the TPP/STEMM program. Within each of the selections the intersections between class, gender and educational opportunity are highlighted.

\section{Educational Aspirations}

During the interviews, we were interested in what motivated teen mothers to enrol in university. Not exclusively, yet consistently, many of the teen mothers are first in family students enrolled in a regional university. In addition, many young mothers came from families and situations that did not value tertiary education. Many of the informants had no direct connection to people with tertiary educational experiences. For example:

We never spoke about going to uni in our house. It was get a job, if you were lucky (Abby, teen mother).

I know children have children at a young age, ... and it's not like that's the end of their life, which is very much felt like it at times for me. I did like school, but then ... So, I thought no ... I'm never going to get back to study, I'm never going to getta education (Bianca, teen mother).

People told me the limitations of my life. Finish year 12 and then it is time to get a job and join the real world. I would have been the first person to finish school and that was the mission (Tanya, teen mother).

The TPP/STEMM program offers adolescent mothers the opportunity to re-engage with their educational pathway to address the disruption associated with pregnancy and post-partem motherhood. An essential part of re-engaging with education is creating strong social networks that offer support, advice and a sense of identity for students considering university after becoming mothers. The program is staffed by teachers, social workers and healthcare professionals invested in seeing this cohort enrol and advance through their university programs. Learning happens in within a community engaged in dialogue and reflections that emerge from their own and shared experiences. Importantly, participating in dialogical activities allows learners to examine how social structures, rather than individual merits or failings, can privilege certain claims to knowledge (Collins \& Bilge 2016). For example:

STEMM provided me with belief when I didn't have any. I didn't think that I could do it, and [my teacher] told me that was a load of xxxx, and that I could do it, and that just because all these awful things had happened in the past, but it didn't mean that's where I was going. She was a friend when I really needed one (Erica, teen mother).

At Uni I met people with different values and understandings. I realised also that I took the fact that I couldn't take study for granted. Studying is a massive privilege (Tanya, teen mother).

For these young women to succeed educational institutions need to align with policy makers and community organisations to the fill the gap between student aspirations and support to ensure that this potential for educational attainment can be nurtured and not derailed by a lack of understanding of the complex nature of being pregnant or mothering. As one teacher said:

There is a pull between the (university) system on campus which is getting tighter and tighter - scheduled/grading/IRMs and the needs of the students in a STEMM classroom. Historically there were periods when we were in unison. We were working together and were on the same page. The Uni understood the needs of the program. One student had a stats exam, breast fed throughout and did really well. If groups of girls wanted to work through the mid semester break and do so at their homes, we supported that. They were astoundingly motivated - doing maths and stats at home with their bubs (STEMM lecturer).

Rather than simply focussing on the effectiveness and efficiencies of schooling, policy makers need to understand education as a social force that keeps pace with social change or transformation. Broadening definitions of educational outcomes beyond technical skills and employment figures, enables citizens to develop the capacity to critically engage in challenging inequities within social systems and make meaningful contributions to society. 


\section{Developing Agency}

Succeeding at university requires persistence as well as a range of other skills and attributes. This research highlights that persisting despite difficulty is one of the major challenges for university students. For many of our participants juggling the expectations of university with their role as teen mothers required both commitment and tenacity. The university experience enables students to reflect on contemporary issues in social life and provides opportunities for students to develop critical skills and the ability to become reflexive (Smith-Battle, 2007). For example:

I think that if I didn't get to a point where I was okay with me, despite all my best efforts to keep pushing through uni, I never would have got there. I never would have finished uni unless I'd dealt with some of the stuff for me (Diana, teen mother).

Participants in the TPP/STEMM program have experienced varying degrees of social disadvantage. In order to address the issue of teen mothers in disadvantaged communities it is imperative to understand the undermining 'social, psychological and structural forces' that can limit parents' potential but also identify those factors that contribute to successful outcomes for young parents and their children (Conn et al., 2017).

There is now greater disparity between student needs and organisational requirements. Fitting it into the 'timetable' etc is BS as there must be many students on campus who need the support, empathy and flexibility that we used to be able to provide to the STEMM students (STEMM lecturer).

As highlighted in the quote above, the TPP/STEMM educational team need to be able to connect with the participants as a way of developing independence and agency that are vital to educational outcomes. The relational connections become a critical element of the success of the program but may also create an unintended tension if students become too dependent on the program.

Importantly, the TPP/STEMM participants move through their student experiences building a broader perspective of issues of social justice. While many of the young women in our sample entered the program feeling stigmatised or disenfranchised as mothers, throughout their student journey many aligned their life aspirations with social change by addressing inequities and system failures. For example:

You have more marginalisation of those groups that are kind of prone to be pushed to the outskirts, young mothers and their kids, and - so I just see without support, it goes keeps going and they get more disengaged and lonelier and then it's harder to then engage back into those systems (Gina, teen mother, now mentor to young mothers).

\section{Promoting a Sense of Self}

The aim of the program is to re-engage adolescent mothers with educational pathways through secondary and tertiary studies. However, beyond the institutional indicators of success which include enrolments, program completions and employment prospects, young mothers have many other reasons for re-engaging in education. For some, it is an opportunity to build a stronger sense of self. Often it is the educational team, rather than the students, that see this indicator, for example:

I wouldn't put individual student outcomes in terms of success or failure because although a young mum might engage initially but then return to their former lifestyle choices. The work that STEMM was able to do in the interim is still enough to plant a seed and although the STEMM team may not personally see the outcome, it can still be the reason that a young mum eventually moves forward towards further education/employment (Lacey, member of the TPP/STEMM team).

Many of the teen mothers in our sample also provided insights into how their sense of self as a young mother was developed through their involvement in the program. Sharing parenting stories and narratives with older, more experienced mothers, allowed some of the participants to normalise their feelings and shape their sense of identity as young mothers. The educational team also modelled positive motherhood roles by sharing their own experiences with their students. This authentic engagement provided alternate perspectives that challenged feelings of stigma, discrimination or marginalisation that many of the young mothers were experiencing. For example:

The staff would share with us what was happening in their children's lives too. That was massive, to know that, we were okay, oh okay you might be in your 30s or 40s and you still lose it with your kid. It's not just me as a young mum that's unable to do 
this because I don't know what I'm doing. You're in your 30s and 40s, you still don't know what you're doing. That makes me feel good. Makes you feel like less of a failure" (Frances, teen mother).

Being authentic was of particular importance teaching young women who have experienced stigma and oppression in the past.

Keeping it real, going with the flow, being flexible, empathic, authentic. Remembering that you have no idea what is going on in people's lives and that studying is a bloody hard journey and not forgetting what student's need. It is hard core. It is draining. The STEMM students can see straight through you. They know who is not genuine. They assume that people won't understand their situation. If you are not on your game - you can lose the students with one word. One more negative comment and they will walk. At STEMM it is never predictable, and the stakes are higher (STEMM lecturer).

\section{Implications}

Mezirow (1991) suggests that all humans are driven to make meaning of the world around them and that when people begin to identify their constructed understandings and make decisions on an informed basis, they can experience transformative thinking. Through transformative thinking students generate a revised or new set of understandings with the benefit of insight to their construction (Christie et al., 2015; Taylor, 2000). This belief in the transformative thinking approach to teaching underpins the TPP/STEMM program.

Three central, interrelated components are required to foster an environment conducive to transformative thinking. First, that learners can identify the constructed nature of their own experiences. Second, that they can engage in a process of critical reflection and third, that they have the opportunity to voice their understandings in a rational discourse (Taylor, 2000). To foster a Transformative Learning approach, educators need to create a safe, open and trusting environment for learning. This environment allows the student and educational team to share their experiences and learn from each other. Then, using instructional practices that support a learner centred approach, the educational team can meet students where they are, and develop activities that encourage exploration of alternative personal perspectives. In the cohort of teen mothers, this is an essential platform to mitigate long-standing experiences of stigma and marginalisation. It is clear that these can at times require delicate facilitation to ensure that transformative learning opportunities are created. To maintain the balance of this environment and optimise transformative learning opportunities the educator needs to be both authentic and empathic in their approach (Barlas, 2001; Taylor, 2000).

Teachers need to be authentic to build relationships and trust within a group setting. A sense of authenticity is foundational in relational practice between students and instructor (Booth, 2012). Building this trust requires the educator to understand authenticity in a range of applications to their role. Authenticity can imply that educators are also engaged in the learning process, experiencing similar expectations and concerns that accompany critical reflection and that they are open to transformative learning experiences. Investing in relationships that have the potential to create a shared dialogue between the student and the educational team creates a clearer understanding of barriers and identifies enablers that promote good learning outcomes.

The transformative process is also a reciprocal one with implications for both learner and instructor (Johnson Bailey, 2012). The reciprocal nature of the learning experience can define the approach to participation within group processes and sharing of authentic reflections or it can be used to define the nature of listening. Educators need to develop skills to be able to "read" between the lines and be open to engendering empathy among themselves and others in the transformative classroom (Schapiro et al., 2012).

\section{Reflections From Teaching in STEMM}

Delivering programs for vulnerable cohorts presents real challenges for educators. Educators will bring their own constructed understandings and that are representative of the individuals' experiences. This requires educators to work actively in identifying their own underlying judgements and preconceived notions that exist within them (Brookfield, 2014). By doing so educators can explore, rather than ignore, latent constructed ways of being with students and actively challenge commonly accepted socialised assumptions. Giving students further insight to the subtle yet pervasive nature of constructed stereotypes. This disclosure and subsequent exposure of an educator provides further authenticity to the relationship that is being created with students. Whilst it is clear that self-disclosure by students or teachers can be an important tool in optimising Transformative 
Learning it can also present challenges to the educator seeking to provide these learning experiences in a safe and supported environment.

- Educators need to not only understand the inherent privilege that accompanies the role of educator and their lived experience, but also the stereotypes that this can perpetuate and the impacts these can have on the learning environment and student experience.

- Engaging with students authentically creates an environment conducive to authentic learning, which is critical when working with students from this cohort.

- Assessment processes and instruction need to be complemented with tailored delivery ensuring students are clear in their understanding of what is required, and the steps needed for success, building the confidence of individuals in their attempts at educational engagement.

- Create an inclusive and flexible learning environment, conscious of the demands that accompany young children and parenting. Students are unable to devote their full attention to learning if they cannot be satisfied that their child's welfare is being met. This can often see students breastfeeding and/or engaging with their children during learning sessions.

- Additional flexibility is required in terms of curriculum: course delivery/pace and assessment, to accommodate the nature of the group's learning needs and unique challenges. Providing this flexibility is fundamental to creating a supportive institutional context for TPP/STEMM students as the time and commitment demands they face often create barriers to their academic success.

- Educators need to build an advocacy network that they can draw upon, as TPP/STEMM students can often encounter multiple barriers to engagement considering their historical exclusion from these environments. Advocating for these students can at times mean assisted engagement in University services and additional liaison with academic staff.

Delivering programs for vulnerable cohorts presents real challenges for educators. Educators will bring their own constructed understandings and that are representative of the individuals' experiences. This requires educators to work actively in identifying their own underlying judgements and preconceived notions that exist within them (Brookfield, 2014). By doing so educators can explore, rather than ignore, latent constructed ways of being with students and actively challenge commonly accepted socialised assumptions. Giving students further insight to the subtle yet pervasive nature of constructed stereotypes. This disclosure and subsequent exposure of an educator provides further authenticity to the relationship that is being created with students. Whilst it is clear that self-disclosure by students or teachers can be an important tool in optimising Transformative Learning it can also present challenges to the educator seeking to provide these learning experiences in a safe and supported environment.

\section{Conclusion}

Education can be transformative. It is critical to society and needs to reflect societal realities as well as inspire social change. In the context of adolescent motherhood, education needs to adapt to embrace transformative teaching and learning, building on critical pedagogy praxis and authenticity in relationships. To be able to do so, education can be transformative and not simply a force of reinforcing structural positions that limit inclusion of marginalised or vulnerable populations. Our research provides an overview of the lived experiences of young mothers who have re-engaged in education following a disruption to their studies. As with all research, there are limitations to acknowledge. First, our accounts are based on a small sample of participants who had direct involvement with one program in a regional university town context. It may be difficult to generalise the findings of this study to other contexts, however, the lessons learnt from the implementation of the program correlate to best practice strategies grounded on critical pedagogy (Brookfield 2014; Hill \& Bilge 2016). Second, participants were only interviewed once, and despite one of the authors being involved in the program, this may have limited the amount of information the participants felt confident in disclosing, which may also be influenced by a degree of social desirability in their responses. This however, does not detract from the frank and thorough accounts of their student experiences as young mothers in the education setting. Further, future studies of this type are welcome as a distinct gap exists in the literature that places the voice of the young mothers into this policy and practice discussions. The young mothers have much to contribute that would better inform policy and practice and their understandings could be further extended with longitudinal studies. 


\section{References}

Allard, A. C., \& Santoro, N. (2008). Experienced teachers' perspectives on cultural and social class diversity: Which differences matter? Equity \& Excellence in Education, 41(2), 200-214. https://doi.org/10.1080/10665680801957253

Barlas, C. (2001, June). Learning-Within-Relationship as Context and Process in Adult Education: Impact on Transformative Learning and Social Change Agency. [Paper presentation] Annual Meeting of the Adult Education Research Conference. Lansing, MI.

Barnett, R. (1997). Higher Education: A critical business. Society for Research into Higher Education and Open University Press.

Bermea, A. M., Toews, M. L., \& Wood, L. G. (2018). "Students getting pregnant are not gonna go nowhere": Manifestations of stigma in adolescent mothers' educational environment. Youth \& Society, 50(3), 423-436. https://doi.org/10.1177\%2F0044118X16661734

Booth, M. (2012). Boundaries and student self-disclosure in authentic, integrated learning activities and assignments. New Directions for Teaching \& Learning, 2012(131), 5-14, doi: 10.1002/t1.20023

Brookfield, S. (2014). Teaching Our Own Racism: Incorporating Personal Narratives of Whiteness into Anti-Racist Practice. Adult Learning, 25(3), 89-95. https://doi.org/10.1002/t1.20023

Butler, K., Winkworth, G., McArthur, M., \& Smyth J. (2010). Experiences and aspirations of younger mothers. Institute of Child Protection Studies.

https://www.dss.gov.au/sites/default/files/documents/06 2012/experiences_aspirations_of_younger_mothers may2012.p df

Carlson, D. L. (2016) Challenges and transformations: childbearing and changes in teens' educational aspirations and expectations. Journal of Youth Studies, 19(5),705-724. https://doi.org/10.1080/13676261.2015.1098771

Christie, M., Carey, M., Robertson, A., \& Grainger, P. (2015), Putting transformative learning theory into practice. Australian Journal of Adult Learning, 55(1), 9-30.

Collins, P. H., \& Bilge, S. (2016). Intersectionality. Polity Press.

Conn, B. M., de Figueiredo, S., Sherer, S., Mankerian, M., \& Iverson, E. (2018). “Our lives aren't over": A strengths-based perspective on stigma, discrimination, and coping among young parents. Journal of Adolescence, 66, 91-100. https://doi.org/10.1016/j.adolescence.2018.05.005

Connor, D. J. (2006). Michael's story: "I get into so much trouble just by walking": Narrative knowing and life at the intersections of learning disability, race, and class. Equity \& Excellence in Education, 39, 154-165. https://doi.org/10.1080/10665680500533942

Crème, P. (1999). A reflection on the education of the 'critical person'. Teaching in Higher Education, 4(4), 461-471. https://doi.org/10.1080/1356251990040403

Duncan, S. (2007). What's the problem with teenage parents? And what's the problem with policy? Critical Social Policy, 27(3), 307-334. https://doi.org/10.1177\%2F0261018307078845

Dunne, G. (2015). Beyond critical thinking to critical being: Criticality in higher education and life. International Journal of Educational Research, 71, 86-99. https://doi.org/10.1016/j.ijer.2015.03.003

Freire, P. (1970). The pedagogy of the oppressed. Herder and Herder.

Goffman, E. (1963). Stigma: notes on the management of spoiled identity. Penguin.

Graham, H., \& McDermott, E. (2005). Qualitative research and the evidence base of policy: insights from teenage mothers in the UK. Journal of Social Policy, 35(1), 21-37. https://doi.org/10.1017/S0047279405009360

Johnson Bailey, B. (2012). Positionality and transformative learning: A tale of inclusion and exclusion. In E. W. Taylor \& P. Cranton (Eds.), Handbook of transformative learning: Theory, research, and practice (pp. 260-271). Wiley.

Kendall, C., Afable-Munsuz, A., Speizer, E., Avery, A., Schmidt, N., \& Santelli, J. (2005). Understanding pregnancy in a population of inner-city women in New Orleans-results of qualitative research. Social Science and Medicine, 60, 297311. https://doi.org/10.1016/j.socscimed.2004.05.007

Irizarry, J. G. (2007). Ethnic and urban intersections in the classroom: Latino students, hybrid identities and culturally responsive pedagogy. Multicultural Perspectives, 9(3), 21-28. https://doi.org/10.1080/15210960701443599

Link, B., \& Phelan, J. (2001). Conceptualizing stigma. Annual Review of Sociology, 27, 363-385. https://doi.org/10.1146/annurev.soc.27.1.363

Major, B., \& O'Brien, L. (2005). The social psychology of stigma. Annual Review of Psychology, 56, 393-421. https://doi.org/10.1146/annurev.psych.56.091103.070137

Mezirow, J. (1991). Transformative dimensions of adult learning. Jossey-Bass

Pillow, W. (2004). Unfit subjects: Educational policy and the teen mother. Routledge. 
Pillow, W. (2006). Teen pregnancy and education: Politics of knowledge, research, and practice. Educational Policy, 20(1), 59-84. https://doi.org/10.1177\%2F0895904805285289

Schultz, K. (2001). Constructing failure, narrating success: Rethinking the "problem" of teen pregnancy. Teachers College Record, 103(4), 582-607.

Seamark, C. J., \& Lingus, P. (2004). Positive experiences of teenage motherhood: A qualitative study. British Journal of General Practice, 54(508), 813-818.

Schapiro, S. A., Wasserman, I. L., \& Gallegos, P. V. (2012). Group work and dialogue: Spaces and processes for transformative learning in relationships. In E. W. Taylor \& P. Cranton (Eds.), Handbook of transformative learning: Theory, research, and practice (pp. 355-372). Wiley.

Smith-Battle, L. (2007). Legacies of advantage and disadvantage: The case of teen mothers. Public Health Nursing, 24(5): 409-420. https://doi.org/10.1111/j.1525-1446.2007.00651.x

Spiggle, S. (1994). Analysis and interpretation of qualitative data in consumer research. Journal of Consumer Research, 21(4), 491-503. https://doi.org/10.1086/209413

Staunaes, D. (2003). Where have all the subjects gone? Bringing together the concepts of intersectionality and subjectification Nordic Journal of Feminist and Gender Research, 11(2), 101-110. https://doi.org/10.1080/08038740310002950

Taylor, E. W. (2000), Fostering Mezirow's transformative learning theory in the adult education classroom: A critical review. Canadian Journal for the Study of Adult Education, 14(2), 1-28. https://cjsae.library.dal.ca/index.php/cjsae/article/view/1929

Taylor, E. W. (2008). Transformative learning theory. In. S. B. Merriam (Ed.) Third update of adult learning. New directions for adult and continuing education, No 119, (pp. 5-15). Jossey-Bass.

Thompson, C. J., (1997). Interpreting consumers: A hermeneutical framework for deriving marketing insights from the texts of consumers' consumption stories. Journal of Marketing Research, 34(4), 438-455. https://doi.org/10.1177\%2F002224379703400403

Watson, L. L., \& Vogel, L. R. (2017). Educational resiliency in teen mothers. Cogent Education, 4(1), 1276009. http://dx.doi.org/10.1080/2331186X.2016.1276009

Yardley, E. (2008). Teenage mothers' experiences of stigma. Journal of Youth Studies, 11(6), 671-684. https://doi.org/10.1080/13676260802392940

\section{Please cite this article as:}

Cheung, L., Kill, E., Turley, J. (2020). Transformative learning: Developing agency, independence and promoting a strong sense of self in teen mothers. Student Success, 11(1), 66-74. https://doi.org/10.5204/ssj.v11i1.1463

This article has been peer reviewed and accepted for publication in Student Success. Please see the Editorial Policies under the 'About' section of the Journal website for further information.

Student Success: A journal exploring the experiences of students in tertiary education

(c) (1) This work is licensed under a Creative Commons Attribution 4.0 International Licence. As an open access journal, articles are free to use with proper attribution. ISSN: 2205-0795 